\title{
Use of Assist Devices to Actuate Pressurized Metered- Dose Inhalers in Elderly Patients with Asthma
}

\author{
Masahiro Hirose (D) · Rieko Kondo · Takahiko Horiguchi
}

Received: September 30, 2020 / Accepted: January 20, 2021 / Published online: February 6, 2021

(c) The Author(s) 2021

\section{ABSTRACT}

Introduction: Some elderly patients experience difficulty when attempting to use pressurized metered-dose inhalers (pMDIs) due to reduced finger muscle strength. However, no studies have investigated the finger muscle strength required for pMDI actuation. Therefore, we created a modified pMDI pinch gauge and examined the finger muscle strength in elderly asthmatic patients with and without the use of a pMDI assist device to push the canister.

Methods: We measured the finger muscle strength $(\mathrm{N})$ required to spray pMDI formulations (Adoair ${ }^{\circledR}$, Alvesco ${ }^{\circledR}$, Flutiform $^{\circledR}$, and Brez$\left.\operatorname{tri}^{\circledR}\right)$ using one hand in healthy individuals. We then similarly measured the finger muscle strength when using the modified pinch gauge in older adults aged 65 years or older with bronchial asthma who used pMDI formulations. Results: The finger muscle strength required to actuate these devices was $29.4 \mathrm{~N}$ or more in healthy individuals. In the older patients with asthma, the finger muscle strength was $38.45 \pm 5.80 \mathrm{~N}$ in men and $31.34 \pm 9.94 \mathrm{~N}$ in women. The finger muscle strength was $\leq 29.4 \mathrm{~N}$ in $6.6 \%$ of men and $40.0 \%$ of women.

Conclusions: Finger muscle strength should be considered when selecting a device for older patients with asthma, and the use of a pMDI assist device to push the canister is recommended in patients with weaker finger muscles.

Keywords: Elderly patients with bronchial asthma; Finger muscle strength; Pinch gauge; pMDI assist device; Pressurized metered-dose inhaler (pMDI)
M. Hirose $(\bowtie) \cdot$ R. Kondo $\cdot$ T. Horiguchi Department of Respiratory Medicine and Clinical Allergy, Fujita Health University, 3-6-10, Otobashi, Nakagawa-ku, Nagoya, Aichi 454-0012, Japan e-mail: hiromasa87@yahoo.co.jp 


\section{Key Summary Points}

\section{Why carry out this study?}

Drugs delivered via pressurized metereddose inhalers (pMDIs) are indispensable for the management of asthma, but there is difficulty in actuating the pMDI, especially in those with reduced finger muscle strength such as older patients; thus, the expected effects for disease control are not obtained in many cases.

To the best of our knowledge, there have been no studies on finger muscle strength in the context of asthma and the delivery of medication by pMDIs.

We aimed to determine the finger muscle strength of older adults with asthma (aged $\geq 65$ years) as compared to healthy individuals using a novel pMDI pinch gauge that we have created with the hypothesis that the force needed to adequately deliver inhaled medications is inadequately generated by older individuals with asthma.

\section{What was learned from the study?}

The finger muscle strength required to spray medication from these devices was $29.4 \mathrm{~N}$ or more in healthy individuals; among the older patients with asthma, it was $38.45 \pm 5.80 \mathrm{~N}$ in men and $31.34 \pm 9.94 \mathrm{~N}$ in women; and it was $29.4 \mathrm{~N}$ or less in $6.6 \%$ of men and $40.0 \%$ of women.

Finger muscle strength should be considered when selecting a device for older patients with asthma, and the use of a pMDI spacer is recommended in patients with weaker finger muscle strength.

\section{DIGITAL FEATURES}

This article is published with digital features, including a summary slide, to facilitate understanding of the article. To view digital features for this article go to https://doi.org/10.6084/ m9.figshare.13615433.

\section{INTRODUCTION}

Inhaled drugs are indispensable for the treatment of asthma [1]. Inhaler devices can be categorized as pressurized metered-dose inhalers (pMDIs), dry powder inhalers (DPIs), and soft mist inhalers. The problem with pMDIs is the difficulty surrounding coordination of actuation and inhalation, but despite an extensive literature review, we found no studies on finger muscle strength required for spraying. Elderly patients often have decreased muscle strength, respiratory function, hearing ability, comprehension, motivation, and sensitivity to symptoms due to aging, and they often have concurrent dementia, neurological diseases, and motor disease; in many cases, the expected effects of treatment are not attained [2]. One report noted that the level of acquisition of inhalation technique in elderly patients aged 75 years or older was similar to that in 5-yearold children [3]. One of the possible causes of this is weak finger muscle strength in the elderly. We have managed patients who could not push a pMDI canister with one hand, which patients in adolescence and middle age can easily do. To the best of our knowledge, there have been no reports of studies that have objectively measured and compared the finger muscle strength required to use a pMDI. Therefore, we created a pMDI pinch gauge (finger muscle strength meter) and compared the finger muscle strength between elderly patients with asthma treated with a pMDI assist device and those treated without a pMDI assist device to push the canister. 


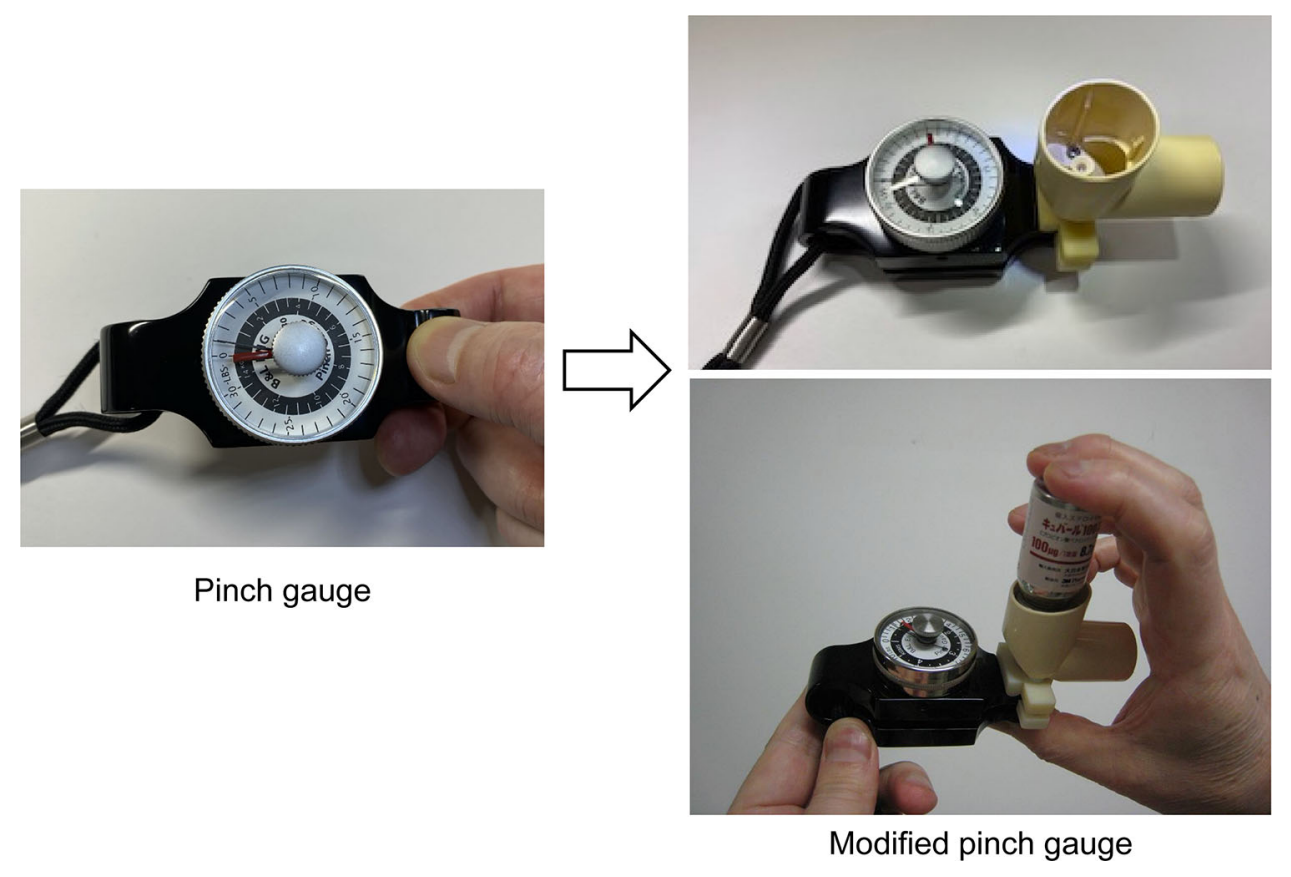

Fig. 1 Creation of a modified pinch gauge

\section{METHODS}

This study was approved by Fujita Health University Medical Research Ethics Committee (14-037) and was performed in accordance with the Helsinki Declaration of 1964 and its later amendments. All study participants provided written informed consent to participate in the study and to publish their data.

A pinch gauge is used to measure the finger muscle strength in patients with conditions such as neuromuscular disease [4]. We created a modified pinch gauge to measure the finger muscle strength required to spray pMDI formulations (Fig. 1). We ordered a custom-made plastic appliance to attach a pMDI formulation canister to the pinch gauge (Model, PG-30; Serial Number, B3S233; manufactured by B\&L Engineering, Santa Ana, CA, USA). Since the unit of measurement for the pinch gauge is lbs, calculation was based on $1 \mathrm{lb}=4.4482 \mathrm{~N}$.

A pMDI was fitted to the plastic part, and the formulation was sprayed with the first finger of the dominant hand placed under the pinch gauge and the second and third fingers placed on the pMDI cylinder; the pressure at that time was measured.
The finger muscle strength required to spray pMDI formulations (Adoair ${ }^{\circledR}$, Alvesco ${ }^{\circledR}$, Flutiform ${ }^{\circledR}$, Breztri ${ }^{\circledR}$ ) using only one hand was measured in healthy individuals (10 men and 10 women; age, 28-58 years; mean age, $40.2 \pm 9.63$ years). The assist devices used with pMDI formulations are shown in Fig. 2. Measurements were performed with and without the use of an assist device. All results are presented as mean \pm standard deviation. Stat View J 5.0 was used for statistical analysis, and $p<0.05$ was considered statistically significant by $t$ test.

Next, finger muscle strength was measured using a modified pinch gauge in 60 elderly outpatients with bronchial asthma, aged 65 years or older, at our institution who had no neuromuscular disease and used pMDI formulations [age 65-94 years; 30 men (mean age $77.40 \pm 7.46$ years) and 30 women (mean age $78.00 \pm 9.05$ years) $]$.

\section{RESULTS}

The finger muscle strength required to spray devices using one hand measured in healthy 


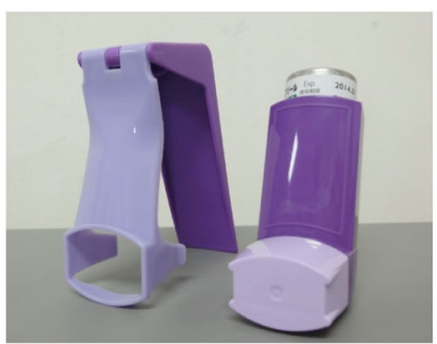

Adoair $^{\circledR}$

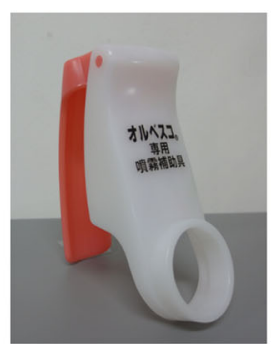

Alvesco ${ }^{\circledR}$

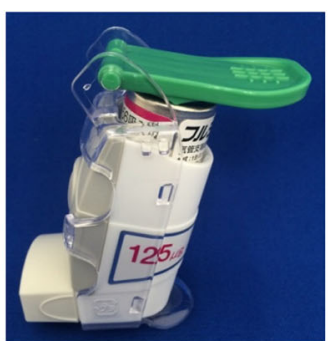

Flutiform $^{\circledR}$

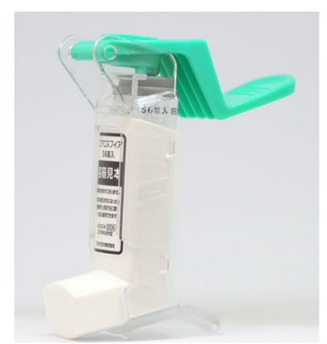

Breztri $^{\circledR}$

Fig. 2 Pressurized metered-dose inhalers (pMDIs) with assist devices to push the canisters

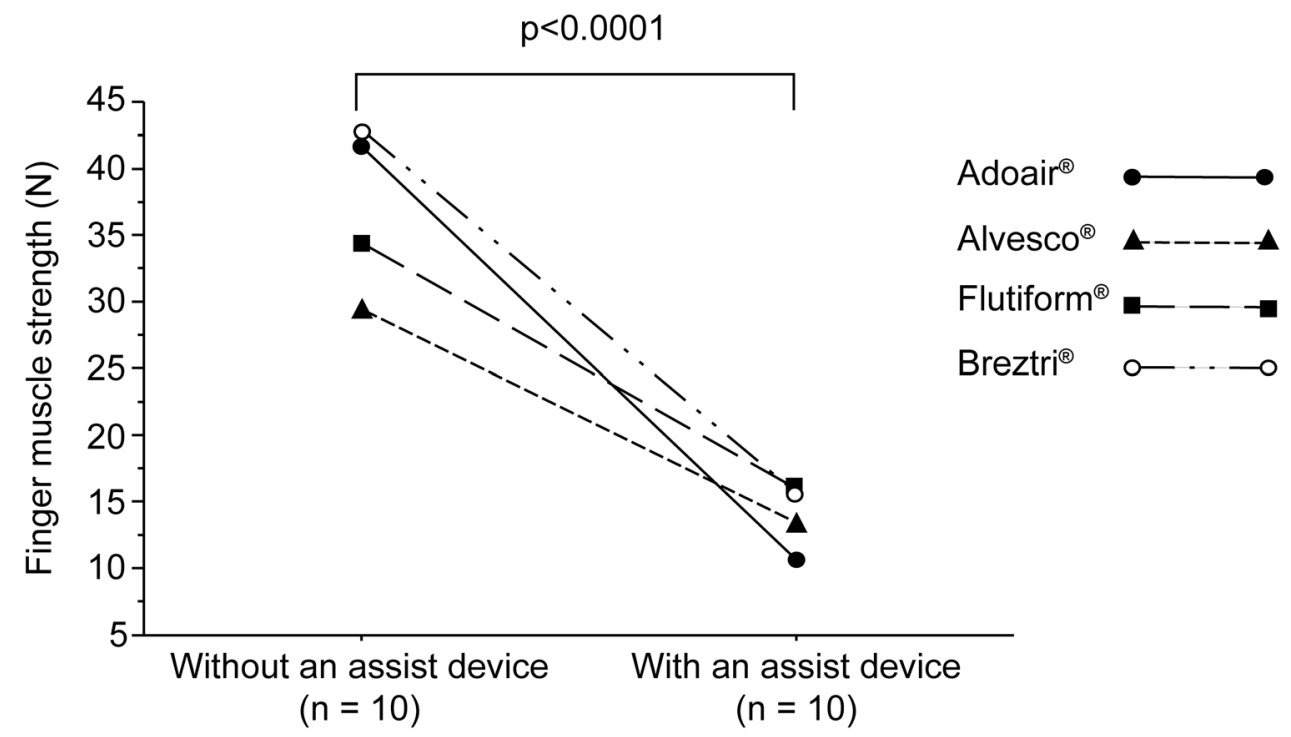

Fig. 3 Measurement of finger muscle strength required to spray pressurized metered-dose inhaler (pMDI) formulations using a modified pinch gauge

individuals using a modified pinch gauge is presented in Fig. 3. Without an assist device, the smallest finger muscle strength was required to spray an Alvesco ${ }^{\circledR}$ pMDI, followed by Flutiform $^{\circledR}$, Adoair $^{\circledR}$, and Breztri ${ }^{\circledR}$. With an assist device, the smallest finger muscle strength was required to spray an Adoair ${ }^{\circledR}$ pMDI, followed by Alvesco $^{\circledR}$, Breztri $^{\circledR}$, and Flutiform ${ }^{\circledR}$ (Table 1). All pMDI formulations could be sprayed using less

Table 1 Measurement of the finger muscle strength required to spray pMDI formulations using a modified pinch gauge in healthy individuals

\begin{tabular}{lll}
\hline & Without an assist device $(\boldsymbol{n}=\mathbf{1 0})$ & With an assist device $(\boldsymbol{n}=\mathbf{1 0})$ \\
\hline Adoair $^{\circledR}$ & $41.7 \pm 0.46 \mathrm{~N}$ & $10.7 \pm 0.64 \mathrm{~N}$ \\
Alvesco $^{\circledR}$ & $29.4 \pm 0.76 \mathrm{~N}$ & $13.7 \pm 0.65 \mathrm{~N}$ \\
Flutiform $^{\circledR}$ & $34.5 \pm 0.62 \mathrm{~N}$ & $16.0 \pm 0.77 \mathrm{~N}$ \\
Breztri $^{\circledR}$ & $42.3 \pm 1.02 \mathrm{~N}$ & $15.6 \pm 0.75 \mathrm{~N}$ \\
\hline
\end{tabular}

$p M D I$ pressurized metered-dose inhaler 


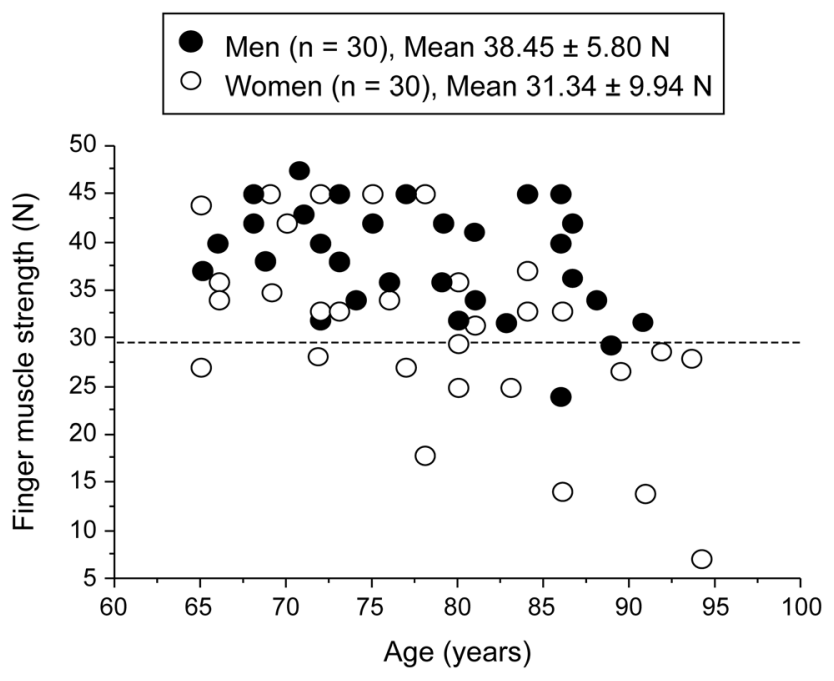

Fig. 4 Measurement of the finger muscle strength in elderly patients using inhalers

finger muscle strength with the use of an assist device.

Figure 4 shows the measurement results of finger muscle strength using a modified pinch gauge in elderly patients with asthma. The mean finger strength was $38.45 \pm 5.80 \mathrm{~N}$ in men $(n=30)$ and $31.34 \pm 9.94 \mathrm{~N}$ in women $(n=30 ;$ Fig. 4$)$. The dotted line indicates the finger muscle strength of $29 \mathrm{~N}$ required for the Alvesco $^{\circledR}$ pMDI, which could be sprayed with the least finger muscle strength. In total, 2/30 (6.6\%) men and $12 / 30(40.0 \%)$ women were unable to reach the required finger muscle strength of $29.4 \mathrm{~N}$ to spray the device; $40 \%$ of women had inadequate finger muscle strength to use a pMDI.

\section{DISCUSSION}

In this study, we created a modified pinch gauge and measured the finger muscle strength required to spray various pMDI formulations (Adoair $^{\circledR}$, Alvesco ${ }^{\circledR}$, Flutiform ${ }^{\circledR}$, and Breztri ${ }^{\circledR}$ ). We found that Alvesco ${ }^{\circledR}$ required the least finger muscle strength of $29.4 \mathrm{~N}$ to spray the formulation, while the other pMDI formulations required a finger muscle strength of $30 \mathrm{~N}$ or more. However, with an assist device to push the canister, all pMDI formulations could be sprayed with finger muscle strengths of $20 \mathrm{~N}$ or lower. The finger muscle strength in elderly patients was $30 \mathrm{~N}$ or lower in $6.6 \%$ of men and $40 \%$ of women, suggesting that spraying pMDI formulations with one hand is impossible without an assist device to push the canister. Therefore, when recommending pMDI formulations to elderly patients with asthma or patients with disorders, such as neuromuscular diseases, it is necessary to confirm whether they are able to spray the sample formulation, using a pinch gauge near the mouth, prior to prescription. The use of the assist device is ideal for patients with weak finger muscle strength.

The number of elderly patients who cannot use devices well is greater than that anticipated by physicians. When selecting a device for elderly patients with asthma, it is necessary to select a device suitable to the patient's medical history [4]. This study demonstrated that a possible solution is to consider the patient's finger muscle strength. Particularly in elderly patients, it is necessary to manually check whether they can use devices without any problems after being prescribed pMDI formulations. In the future, we would like to investigate whether the use of a pMDI assist device in patients with weak finger muscle strength would lead to an improvement in asthma control. 


\section{CONCLUSIONS}

We found that finger muscle strength should be considered when selecting a device for older patients with asthma, and that the use of a pMDI assist device to push the canister is recommended for patients with weaker finger muscle strength. As the present investigation is a basic study, in the future, we plan to investigate the clinical efficacy of the pMDI assist device by comparing the outcomes of patients treated with and without the use of such a device. We also plan to analyze the exacerbation control to contribute to the improvement of quality of life of patients treated for asthma.

\section{ACKNOWLEDGEMENTS}

We would like to thank all the study participants for their involvement.

Funding. No funding or sponsorship was received for this study or publication of this article. The Rapid Service Fee was funded by the authors.

Authorship. All named authors meet the International Committee of Medical Journal Editors (ICMJE) criteria for authorship for this article, take responsibility for the integrity of the work as a whole, and have given their approval for this version to be published.

Disclosures. Masahiro Hirose, Rieko Kondo, and Takahiko Horiguchi have nothing to disclose.

Compliance with Ethics Guidelines. This study was approved by Fujita Health University Medical Research Ethics Committee (14-037) and was performed in accordance with the Helsinki Declaration of 1964 and its later amendments. All study participants provided written informed consent to participate in the study and to publish their data.
Data Availability. The datasets generated during and/or analyzed during the current study are available from the corresponding author on reasonable request.

Open Access. This article is licensed under a Creative Commons Attribution-NonCommercial 4.0 International License, which permits any non-commercial use, sharing, adaptation, distribution and reproduction in any medium or format, as long as you give appropriate credit to the original author(s) and the source, provide a link to the Creative Commons licence, and indicate if changes were made. The images or other third party material in this article are included in the article's Creative Commons licence, unless indicated otherwise in a credit line to the material. If material is not included in the article's Creative Commons licence and your intended use is not permitted by statutory regulation or exceeds the permitted use, you will need to obtain permission directly from the copyright holder. To view a copy of this licence, visit http://creativecommons.org/licenses/by$\mathrm{nc} / 4.0 /$.

\section{REFERENCES}

1. Global Initiative for Asthma. 2018 GINA main report. 2018 GINA Report, Global Strategy for Asthma Management and Prevention [Internet] [Updated 2020]. https://ginasthma.org/gina-reports/. Accessed 17 May 2018.

2. Japanese Society of Allergology. Asthma prevention and management guideline 2018. Tokyo: Kyowa Kikaku Ltd.; 2018. p. 193-4.

3. Hoskins G, McCowan C, Neville RG, Thomas GE, Smith B, Silverman S. Risk factors and costs associated with an asthma attack. Thorax. 2000;55:19-24.

4. Akamatsu K, Fukai K. The relationship between finger touch-pressure, pinch force, and grip strength and symptoms of numbness in the elderly. Jpn J Nurs Art Sci. 2014;13:108-16. 